\title{
HUBUNGAN TIPE KEPRIBADIAN DENGAN KEJADIAN DEPRESI PADA LANSIA DI UPT PSLU JOMBANG - PARE KEDIRI
}

\author{
Nurhidayah, Ismu Basuki, Endik mufidatul Fitriah \\ Stikes Ganesha Husada Kediri \\ nurhida15@gmail.com
}

\begin{abstract}
The depression is one of the form of disturbance that gave rise to natural feeling symptoms indicating the dysfunction ofaphek, emotion, the mind, and a common activity. The purpose of this research is to know relations with type personality scene depression in elderly at UPT PSLU Jombang Pare Kediri. The research design that is used is analytic the correlation with the kind of research cross sectional. The population research is all for the elderly are at UPT PSLU Jombang Pare Kediri selected from as many as 73 seniors taken using a technique simple random of sampling. Variable free is a type personality and variable bound is the incident depression. Adaption of the data carried out using a questionnaire and questionnaires. Data expressed in the scale of nominal and ordinal as will analyzed with a test of the spearman rank with alpha 0,05. The research result obtained the majority of respondents had a role with two categories of extroverted that is as much as 40 respondents $(54,8 \%)$. Half of the respondents suffer from depression being level that is as many as 31 respondents $(42,5 \%)$. Of the total 73 respondents and there is a relationship with type personality scene depression in elderly at UPT PSLU Jomabang Pare Kediri ( Phi with p value $=0,000<0.05$ then Ho rejected). The conclusion of this research is there is a relationship with type personality scene depression in elderly at UPT PSLU Jombang Pare Kediri. For it expected an improvement in environmental adjustment to from type personality extroverted ongoing form through existing activities in UPT PSLU.
\end{abstract}

Keywords : the type personality, the incident depression, the elderly

\section{PENDAHULUAN}

Lansia merupakan kelompok yang rentan terhadap perubahan-perubahan fisik, biologis, psikologis serta depresi (Kompas, 2008). Batasan lansia menurut Organisasi Kesehatan Dunia (WHO) yaitu Usia pertengahan (middle age) yaitu kelompok usia 45-59 tahun, Usia lanjut (elderly) antara 60-74 tahun, Usia lanjut tua (old) antara 75-90 tahun, Usia sangat tua (very old) diatas 90 tahun. Selain faktor fisik, biologis dan psikologis, Depresi merupakan salah satu bentuk gangguan alam perasaan yang memunculkan gejala yang mengindikasikan adanya disfungsi afek, emosi, pikiran dan aktivitas-aktivitas umum (Copel,2007).
Kepribadian adalah sesuatu organisasi yang dinamis dari sistem-sistem psikologis di dalam individu yang menentukan penyesuaian yang khas terhadap lingkungannya (Sunaryo, 2004)

Berdasarkan study penelitian yang dilakukan peneliti di UPT PSLU Jombang-Pare Kediri didapatkan jumlah pengguni panti sebanyak 85 lansia. (Perempuan 56 orang dan laki-laki 29 orang) diantara lansia tersebut yang mengalami depresi sebanyak 20 lansia $(17 \%)$ diantaranya 15 lansia perempuan (3\%) dan 5 lansia laki-laki (1\%). Banyaknya lansia yang menderita depresi disebabkan interaksi faktor biologis, psikologis dan sosial.(Ingram, 2003). 
Melihat keragaman masalah atau dampak akibat depresi pada lansia dan dengan adanya penghuni panti yang mengalami depresi yang mempunyai tipe kepribadian ekstrovert dapat mempertahankan berinteraksi sosial yang tetap aktif dan produktif, mempertahankan kemandirian, tipe kepribadian introvert diharapkan lebih meningkatkan kepercayaan diri, bisa lebih aktif dalam bersosialisasi dengan orang banyak, sedangkan tipe kepribadia ambivert diharapkan lebih bisa meyakinkan diri sendiri untuk memulai segala sesuatunya.

\section{METODE PENELITIAN}

Pada penelitian ini desain yang digunakan adalah analitik korelasi dengan jenis penelitian cross sectional. Suatu penelitian dimana variabel-variabel yang termasuk faktor resiko dan variabelvariabel efek diobservasi sekaligus pada waktu yang sama (Nursalam, 2008).

Penelitian ini dilaksanakan tanggal 03 April 2015 sampai 02 Mei 2015. Tempat penelitian dilaksanakan di UPT PSLU Jomabng Pare Kediri.

Dalam penelitian ini menggunakan simple random sampling adalah setiap anggota atau unit dari populasi mempunyai kesempatan yang sama untuk diseleksi sebagai sampel.

Instrumen adalah alat yang digunakan untuk pengumpulan data (Alimul, 2007). Jenis instrumen yang digunakan dalam penelitian ini adalah lembar kuesioner. Pengumpulan data dengan kuesioner dilakukan ketika peneliti ingin memperoleh data kecemasan. Setelah semua data terkumpul, diperiksa kelengkapannya. Kemudian hasil pengisian kuesioner dianalisa dengan menggunakan tabel distribusi yang dikonfirmasikan dalam bentuk distribusi frekuensi, prosentasi dan narasi.

\section{HASIL DAN PEMBAHASAN}

\section{Hasil}

Tabel 5.1 Karakteristik Responden Berdasarkan Usia di UPT PSLU Jombang Pare Kediri Bulan Mei 2015

\begin{tabular}{cccc}
\hline No. & Umur & f & $\%$ \\
\hline 1 & 60-69 Tahun & 19 & 26,0 \\
2 & 70-79 Tahun & 32 & 43,8 \\
3 & 80-89 Tahun & 22 & 30,1 \\
\hline & Total & 73 & 100 \\
\hline
\end{tabular}

Berdasarkan tabel 5.1 diatas diketahui hampir setengah responden berusia 70-79 tahun yaitu sebanyak 32 responden $(43,8 \%)$ dari total 73 responden.

Tabel 5.2 Distribusi $\quad$ Frekuensi Responden Berdasarkan Jenis Kelamin di UPT PSLU Jombang Pare Kediri Bulan Mei 2015

\begin{tabular}{cccc}
\hline No & Jenis Kelamin & f & $\%$ \\
\hline 1 & Laki-laki & 29 & 39,7 \\
2 & Perempuan & 44 & 60,3 \\
\hline & Total & 73 & 100 \\
\hline
\end{tabular}

Berdasarkan tabel 5.2 diketahui sebagian besar responden berjenis kelamin perempuan yaitu sebanyak 44 responden $(60,3 \%)$ dari total 73 responden.

Tabel 5.3 Distribusi Frekuensi Responden Berdasarkan Pendidikan di UPT PSLU Jombang Pare Kediri Bulan Mei 2015

\begin{tabular}{clcc}
\hline No. & Pendidikan & $\mathrm{f}$ & $\%$ \\
\hline 1 & SD & 30 & 41,1 \\
2 & SMP & 23 & 31,5 \\
3 & SMA & 20 & 27,4 \\
4 & PT & 0 & 0,0 \\
\hline & Total & 73 & 100
\end{tabular}

Berdasarkan tabel 5.3 diketahui hampir setengah responden berpendidikan SD yaitu sebanyak 17 responden $(41,1 \%)$ dari total 73 responden. 
Tabel 5.4 Tipe Kepribadian pada Lansia di UPT PSLU Jombang Pare Kediri Bulan Mei 2015

\begin{tabular}{cccc}
\hline No. & $\begin{array}{c}\text { Tipe } \\
\text { Kepribadian }\end{array}$ & $\mathrm{f}$ & $\%$ \\
\hline 1 & Ekstrovert & 40 & 54,8 \\
2 & Ambivert & 18 & 24,7 \\
3 & Introvert & 15 & 20,5 \\
\hline & Total & 73 & 100 \\
\hline
\end{tabular}

Berdasarkan tabel 5.4 diketahui sebagian besar responden tipe kepribadiannya termasuk kategori ekstrovert yaitu sebanyak 40 responden $(54,8 \%)$ dari total 73 responden.

Tabel 5.5 Kejadian Depresi pada Lansia di UPT PSLU Jombang Bulan Mei 2015

\begin{tabular}{|c|c|c|c|}
\hline No. & Depresi & $\mathrm{f}$ & $\%$ \\
\hline 1 & Berat & 19 & 26,0 \\
\hline 2 & Sedang & 31 & 42,5 \\
\hline 3 & Ringan & 14 & 19,2 \\
\hline 4 & Tidak Depresi & 9 & 12,3 \\
\hline & Total & 73 & 100 \\
\hline
\end{tabular}
diketahui hampir setengah responden mengalami depresi tingkat sedang yaitu sebanyak 31 responden $(42,5 \%)$ dari total 73 responden.

\section{Pembahasan}

\section{Tipe Kepribadian pada Lansia}

Jika sebagian besar responden tipe kepribadiannya termasuk kategori ekstrovert, maka orang ini lebih senang bersama orang lain. Hal ini dapat dipengaruhi oleh factor keturunan misalnya karena orang tuanya memang suka bersosialisasi dengan orang lain sehingga anak cenderung meniru gaya berteman orang tuanya. Faktor lain bias karena faktor pengalaman. Seseorang yang memiliki banyak pengalaman berhubungan dengan orang lain, pengalaman bekerja dengan banyak orang dan sejenisnya akan berpengaruh terhadap kepribadiannya yang akan senang bersama dengan orang lain. Orangnya lebih supel, mudah menyesuaikan diri dengan lingkungan yang baru, tidak mudah stress atau depresi. Oleh kerannya meskipun saat ini berasa dip anti asuhan, orang dengan tipe ini akan dengan mudah menyesuaikan diri dengan lingkungan yang baru ditempatinya ini. Hal ini akan mengurangi perasaan terbuang yang dapat menyebabkan depresi.

\section{Kejadian Depresi pada Lansia}

Didapatkannya setengah responden mengalami depresi tingkat sedang dapat dipengaruhi oleh berbagai faktor. Sebagaimana telah diuraikan di atas bahwa pada lansia depresi utamanya terkait dengan berbagai penyakit yang di alaminya. Pada umumnya lansia mengalami penyakit degeneratif yang umumnya penyembuhannya butuh waktu panjang dan fatality rate-nya juga rendah. Kondisi ini meskipun menimbulkan respon ketakutan namun tidak menimbulkan takut yang luar biasa sehingga meskipun ada perasaan depresi tidak sampai depresi tingkat berat melainkan hanya sampai kategori sedang.

Faktor lain yang berpengaruh adalah usia responen. Berdasarkan hasil penelitian diketahui hampir setengah responden berusia 70-79 tahun. Pada umumnya seseorang dengan usia ini telah siap menghadapi kematian. Oleh karenanya ketika menghadapi penyakit degeneratif selama menjadi lansia, merekla akan menghadapinya dengan lapang dada. Penerimaan ini akan berpengaruh terhadap ketakutan yang tidak luar biasa, sehingga meskipun menimbulkan depresi maka depresi yang dialami hanya sampai pada kategori sedang.

\section{Hubungan Tipe Kepribadian dengan Kejadian Depresi pada Lansia}

Ada hubungan tipe kepribadian dengan kejadian depresi pada lansia di UPT PSLU Jombang-Pare Kediri (Phi dengan $p$ value $=0,000<0,05$ maka Ho ditolak). Tingkat hubungan termasuk 
kategori cukup kuat dan positif ( $\mathrm{Phi}_{\text {hitung }}=$ 0,652), artinya semakin ekstrovert maka depresinya semakin rendah dan sebaliknya semakin introvert maka depresinya semakin berat.

Jika hasil penelitian menunjukkan ada hubungan tipe kepribadian dengan kejadian depresi pada lansia, maka hal ini disebabkan dengan tipe kepribadian yang berbeda maka akan berbeda pula di dalam merespon masalah psikologis dari lingkungan. Orang dengan tipe kepribadian introvert tentunya lebih berisiko mengalami depresi karena memiliki rasa kurang percaya diri, ada kecenderungan perenung/pemikir, suka menyendiri, dan ada kecenderungan membayangkan kesukaran dalam hidup. Berbagai hal ini merupakan pemicu yang seringkali menimbulkan depresi. Berbeda dengan seseorang yang memiliki kepribadian eksrovert yakni orang yang mudah bergaul, sifatnya terbuka, bersahabat, menyenangkan, aktif dan spontan. Orang dengan tipe demikian ini akan mudah menyesuaikan dengan lingkungan, mudah menghadapi masalahnya sehingga tidak mudah stres atau depresi. Jadi dalam hal ini sifat dasar atau tipe kepribadian berhubungan dengan kejadian depresi yang dialaminya.

\section{KESIMPULAN DAN SARAN}

\section{Kesimpulan}

1. Sebagian besar responden tipe kepribadiannya termasuk kategori ekstrovert.

2. Setengah responden mengalami depresi tingkat sedang

3. Ada hubungan tipe kepribadian dengan kejadian depresi pada lansia di UPT PSLU Jombang-Pare Kediri.

\section{Saran}

1. Bagi Responden

Diharapkan agar responden segera menyesuaikan diri dengan lingkungan di PSLU dan bergaul dengan semua penghuni sehingga dapat mengurangi perasaan sendiri, perasaan terbuang, ingat dengan penyakitnya dan berubah ke dalam suasana menyenangkan.

2. Bagi Tempat Penelitian

Diharapkan agar petugas di UPT PSLU memberikan pendekatan yang berbeda kepada penghuni sesuai dengan tipe kepribadian masingmasing. Prioritas adalah kepada mereka dengan tipe kepribadian introvert karena lbih berisiko depresi. Menjalin komunikasi, banyak membantu mereka akan meringankan beban psikologisnya sehingga dapat mengurangi depresinya.

3. Bagi Institusi Pendidikan

Diharapkan agar institusi pendidikan memberikan muatan khusus kepada mahasiswa keperawatan dalam penanganan lansia (gerontik) dengan teori maupun praktek di UPT PLSU agar mahasiswa memiliki pengalaman nyata merawat lansia sesuai tipe kepribadiannya.

4. Bagi Peneliti Selanjutnya

Diharapkan agar peneliti selanjutnya melakukan kajian berbagai variabel yang dapat berpengaruh terhadap kejadian depresi pada lansia, misalnya dkungan keluarga, riwayat kehidupan masa lalunya, atau faktor lainnya selain tipe kepribadian.

\section{DAFTAR PUSTAKA}

Anton. S. P. 2010. Pengaruh Terapi Kognitif dan Senam Latih Otak Terhadap Tingkat Depresi dengan Harga Diri Rendah Pada Klien Lansia Di Panti Tresna Werda Bakti Yuswa Natar Lampung. Skripsi, Program Studi Magister Ilmu Keperawatan Kekhususan Keperawatan Jiwa Fakultas Ilmu Keperawatan Universitas Indonesia. Depok.

Bandiyah, S. 2009. Lanjut Usia dan Keperawatan Gerontik. Yogjakarta : Nuha Medika. 
Dwi.S.P.2013.Ragam Tes Psikologi: untuk Pelajar/Mahasiswa, CPNS/Karyawan, dan Umum. Yogyakarta: Diva Press.

Geriatric Syndromes and Assessment in Older Cancer Patients :Page 2 of 3. http://www.Cancernetwork.com (diakses 2 Desember 2014)

Geriatric Depression Scale (GDS). http://www.patient.co.uk (diakses2 Desember 2014)

Mengenali Depresi pada Usia Lanjut Penggunaan Geriatric Depression Scale (GDS) Untuk Menunjang Diagnosa. http://www.kalbemed.com (diakses 2 Desember 2014)

Nursalam. 2008. Konsep Dan Penerapan Metodologi Penelitian Ilmu Keperawatan: Pedoman Skripsi, Tesis, Dan Instrumen Penelitian Keperawatan. Jakarta: Salemba Medika.

Nursalam, 2008 Konsep dan Penerapan Metodologi Penelitian Ilmu Keperawatan VIII. Jakarta: Salemba Medika

Priyoto. 2014. Konsep Manajemen Stress. Yogyakarta: Nuha Medika.

Sugiyono. 2011. Statistika untuk Penelitian. Bandung: CV Alfabeta.

Supriani, Anik. 2011. Tingkat Depresi Pada Lansia Ditinjau Dari Tipe Kepribadian dan Dukungan Sosial Di UPT Panti Werdha Mojopahit Mojokerto Dan Jombanng. Skripsi, Program Pascasarjana Universitas Sebelas Maret. Surakarta.

Setyono, R. 2011. Psikologi Kepribadian. Edisi Revisi. Malang. UMM press.
Setiadi. 2007. Konsep dan Penulisan Riset Keperawatan. Yogyakarta : Graha Ilmu.

Soegiyono. 2009. Metode Penelitian Kuantitatif Kualitatif dan R \& D. Bandung : CV Alfabeta.

Syamsu, dan A. Jundika. 2008. Teori Kepribadian. Bandung: PT Remaja Rosdakarya.

The Geriatric Depression Scale (GDS). http://www.medscape.com (diaksess 2 Desember 2014) 